\title{
The effect of monetary incentive in paired associate learning using an absolute method'
}

\author{
WILLARD HARLEY, JR. \\ UNIVERSITY OF CALIFORNIA, SANTA BARBARA
}

\begin{abstract}
Abstraet
The design, apparatus, and stimulus materials of an earlier experiment (Harley, 1965) was duplicated with two exceptions: (1) An absolute method was used in the place of a differential method, and (2) each S was tested to a criterion of 3 consecutive correct trials. The results indicated that the magnitude of incentive had no effect upon learning which was consistant with many animal learning studies summarized by Pubols (1960). Learning was found to be more closely related to learning time (trials $x$ exposure time) than trials.
\end{abstract}

\section{Introduction}

Pubols' review of animal learning literature was instrumental in providing a systematic structure to the area of incentive effects in learning. Many of the conclusions drawn by Pubols were based on few studies and were considered highly tentative. But due to the systematic way in which the area was presented, the research needs became clear and the area has developed at a rapid rate. Although Pubols limited himself to animal learning (probably because of the lack of literature concerned with the effect of incentives upon human learning and performance), much of the systematic structure presented by Pubols can be applied directly to human learning.

In an attempt to apply Pubols' scheme to human learning, Harley (1965) investigated the effect of monetary incentive upon paired associate learning using a differential method. Pubols found that animal learning studies utilizing a differential method generally agreed that for an animal trained to discriminate between the incentives, learning seemed to he some direct function of the magnitude of the incentive. Harley (1965) found the same relationship in human paired associate learning. But he also found that this relationship was limited to particular stimulus presentation conditions.

Pubols also summarized animal studies utilizing an absolute method to determine the effects of incentive magnitude upon learning. He reported that with the exception of sucrose studies, incentive magnitude generally was not found to have an effect upon learning.

Since incentive magnitude was seen to have an effect upon paired associate learning with the differential method, it seemed appropriate to investiage whether or not an effect could be found with the absolute method in human learning. This study is an attempt to make such an investigation.

\section{Method}

Eighty students enrolled in an introductory psychology course at the University of California, Santa Barbara served as Ss. They volunteered for the experiment and did not know that they might be paid.

The apparatus and stimuli were literally the same as those used by Harley (1965). The background colors remained the same although with the absolute method they serve no particular purpose.

The procedure was the same as in the differential study with these exceptions: (1) After the basic instructions which were the same as those used by Harley (1965), each $S$ in the reward group was told that after the experiment he would receive 25 cents for each response word correctly anticipated on one predetermined trial or list presentation. (2) Each S was tested until he reached a criterion of three consecutive correct trials.

The $2 \times 2$ design used in the differential method study was carried out in this study as well. The design compared the effects of two values of monetary incentive ( 0 cents and 25 cents) and two R-S intervals (4 sec. and 1.3 sec.).

\section{Results}

Three experimenters gathered the data. T-tests showed that there were no significant differences in total errors between experimenters for all four groups tested.

A $2 \times 2 \times 19$ analysis of variance with repeated measures was performed on the data which represented scores taken at equal learning times (trials $\mathbf{x}$ exposure time) for all groups (as was done in the analysis of the differential method study). Equal trial intervals were not considered in the analysis since learning seemed to be related to the total amount of learning time rather than the total number of trials or overt recitations. This point is explained in more detail below.

The results of the analysis indicated that all main effects and interaction effects failed to reach significance with the expected exception of the main effect of total learning time.

Figures 1 and 2 represent the mean percent of trigrams which were correctly anticipated as a function of trials, the abscissas being scaled for equal time intervals. Figure 1 represents the data for the $4 \mathrm{sec}$. R-S interval group and Fig. 2 and $1.3 \mathrm{sec}$. R-S interval group.

\section{Discussion}

To summarize, while the differential method showed an effect of incentive magnitude upon paired associate learning, the absolute method has failed to detect such an effect. These results are consistant with 


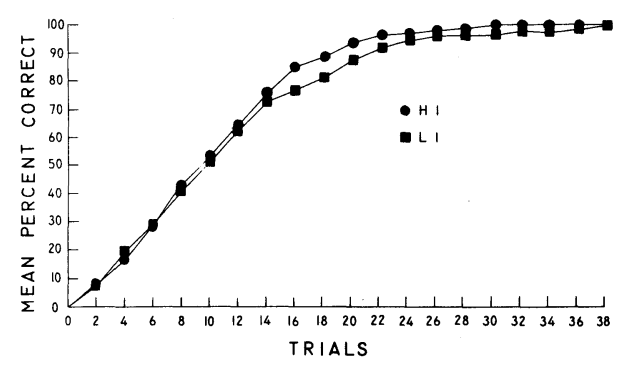

Fig. 1. Mean percent correct responses as a function of trials in the 4 sec. $R-S$ interval situation. Circles indicate high incentive group and squares low incentive.

the findings of many investigators in animal learning as reported by Pubols (1960).

A study recently published by Nodine (1965) is relevant to the question of whether or not trials or learning time (trials $x$ exposure time) should be used as the independent variable in paired associate learning studies. As has been seen in both the differential and absolute method studies in human learning, the total learning time was invariate with respect to variations in $\mathrm{R}-\mathrm{S}$ interval whereas the number of trials or covert recitations varied inversely with variations in the $\mathrm{R}-\mathrm{S}$ interval (averaging the reward and nonreward groups). But in these studies only the $\mathrm{R}-\mathrm{S}$ interval was varied. Nodine reported the same effect with variations in the $\mathrm{R}-\mathrm{S}$ interval (his "St-R duration') holding the S-R interval constant (his "St duration"). However, he also reported that variations in the S-R interval, holding the $\mathrm{R}-\mathrm{S}$ interval constant,

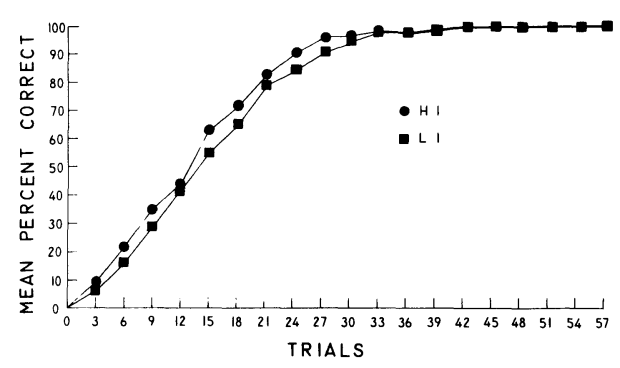

Fig. 2. Mean percent correct responses as a function of trials in the $1.3 \mathrm{sec}$. R-S interval situation. Circles indicate high incentive group and squares low incentive.

had a significant effect upon total learning time. Therefore, it may be tentatively concluded that total learning time may be a better independent variable in paired associate learning only when the S-R interval or anticipation interval is held constant.

\section{References}

Harley, W. F., Jr. The effect of monetary incentive in paired associate learning using a differential method. Psychon. Sci., $1965,2,377-378$.

Nodine, C. F. Stimulus durations and stimulus characteristics in paired associate learning. J. exp. Psychol., 1963, 66, 100-106. Nodine, C. F. Stimulus durations and total learning time in paired associate learning. J. exp. Psychol., 1965, 69, 334-336.

Pubols, B. H., Jr. Incentive magnitude, learning, and performance in animals. Psychol. Bull., 1960, 57, 89-115.

\section{Note}

1. The author is grateful to Jerrold Takahashi and Gretchen Timmermans for their assistance in collecting the data. He is also indebted to David M. Messick for his constructive assistance in the design of the experiment. 